\title{
LETTERS
}

\section{Antihypertensive Medication Adherence Stroke and Death}

To the Editor:-I read with great interest the recent articles by Fischer et al. ${ }^{1}$ and Bailey et al. ${ }^{2}$ which describe the extent of primary non-adherence and document the adverse impact of non-adherence among those with hypertension. Bailey et al. ${ }^{2}$ conclude that by increasing adherence by one pill per week for a once-a-day regimen the hazard of stroke could be reduced by $8-9 \%$ and death by $7 \%$. The public health impact of nonadherence should not be minimized.

I agree with Fischer et al. ${ }^{1}$ that e-prescribing could improve adherence. In 2006, we interviewed 276 clinicians and staff in 64 practices using one of six e-prescribing products. When asked about e-prescribing software with the capability of alerting the physician when the patient has not picked up a prescription, $47 \%$ reported that would be very useful. Yet, these data run counter to the real experience of beta testing eprescribing in 2003 in Rhode Island. The original plan was to alert the prescriber when prescriptions were not picked up (e.g. "the leakage"). Messages were delivered to prescribers; the physicians overwhelmingly (and successfully) argued to turn such messaging off due to the high volume of alerts. Based on these contraditory findings and previous research, ${ }^{3}$ physicians seem to underestimate the extent of the non-adherence problem.

Design of interventions must be done carefully. When probing deeper, we found that $75 \%$ said they would call the patient if the e-prescribing software alerted them that their

Published online May 4, 2010 patient did not pick up a prescription that would have serious medical consequences if not taken. Given the extent of nonadherence, how would busy clinicians even have time to do so? Concerns about liability should not be underestimated. How to deal with these issues in the design of interventions to improve medication adherence is non-trivial.

Kate Lapane, PhD, Virginia Commonwealth University, 830 East Main Road, Richmond, VA 23298, USA (e-mail: kllapane@vcu.edu).

\section{REFERENCES}

1. Fischer MA, Stedman MR, Lii J, Vogeli C, Shrank WH, Brookhart MA, Weissman JS. Primary medication non-adherence: analysis of 195,930 electronic prescriptions. J Gen Intern Med. 2010 Feb 4. [Epub ahead of print].

2. Bailey JE, Wan JY, Tang J, Ghani MA, Cushman WC. Antihypertensive medication adherence, ambulatory visits, and risk of stroke and death. $2010 \mathrm{Feb}$ 18. [Epub ahead of print].

3. Lapane KL, Dubé CE, Schneider KL, Quilliam BJ. Misperceptions of patients vs. providers regarding medication-related communication issues. Am J Manag Care. 2007;13(11):613-8.

J Gen Intern Med 25(8):762 DOI: $10.1007 / \mathrm{s} 11606-010-1378-\mathrm{x}$

(C) Society of General Internal Medicine 2010 